Pacific Journal of Mathematics

ON THE REST POINTS OF A NONLINEAR NONEXPANSIVE 


\title{
ON THE REST POINTS OF A NONLINEAR NONEXPANSIVE SEMIGROUP
}

\author{
CHI-LIN YEN
}

Let $X$ be a reflexive Banach space and $T$ a nonlinear nonexpansive semigroup on $X$. The results which we shall prove are the following:

Theorem 1. Suppose that for any closed convex set $M$ with the property that $T(t) M \cong M$ for all $t \geqslant 0, M$ contains a precompact orbit. Then $T$ has a rest point. Moreover, the set of all rest points of $T$ is connected.

THEOREM 2. Suppose that $X$ is strictly convex and $T$ has a bounded orbit. If there is an unbounded increasing sequence $\left\{u_{i}\right\}$ of positive numbers and point $x$ such that $\lim _{i \rightarrow \infty} T\left(u_{i}\right) x$ exists then $T$ has a rest point. Moreover, if $\left\{t_{i}\right\}$ is an unbounded increasing sequence of positive numbers such that

$$
y=w-\lim _{i \rightarrow \infty} \frac{1}{t_{\imath}} \int_{0}^{t_{i}} T(t) x d t
$$

exists, then $y \in F$.

Let $X$ be a Banach space. By a nonlinear nonexpansive strongly continuous semigroup $T$ on $X$ (or briefly, a semigroup $T$ on $X$ ) we mean that $T$ is a mapping from $[0, \infty) \times X$ into $X$ such that

(i) for any $x \in X, t_{1} \geqslant 0$, and $t_{2} \geqslant 0, T\left(t_{1}\right) T\left(t_{2}\right) x=T\left(t_{1}+t_{2}\right) x$;

(ii) for any $x \in X, \lim _{t \rightarrow 0^{+}} T(t) x=T(0) x=x$;

(iii) for any $x \in X, y \in X$, and $t \geqslant 0,|T(t) x-T(t) y| \leqslant|x-y|$.

Throughout this paper $T$ will denote a semigroup on $X$. We shall give some definitions as follows:

(1) For $x \in X$ the orbit of $x$ is the set $O_{x}=\{T(t) x ; t \geqq 0\}$

(2) $F=\{x ; T(t) x=x$ for all $t \geqslant 0\}$, and if $x \in F$ then $x$ is called a rest point of $T$.

(3) $P=\left\{x\right.$; there is $t_{0}>0$ such that $\left.T\left(t_{0}\right) x=x\right\}$.

(4) $A=\left\{x ; O_{x}\right.$ is precompact $\}$.

(5) $L=\left\{x\right.$; there is a sequence $\left\{t_{i}\right\}$ of positive numbers such that $t_{i} \uparrow \infty$ and $\lim _{i \rightarrow \infty} T\left(t_{i}\right) x$ exists $\}$.

Clearly, $L \supseteqq A \supseteqq P \supseteqq F$. Moreover, if $F \neq \phi$ then $O_{x}$ is bounded for all $x \in X$. The question arises "Is the converse true?" M. Crandall and A. Pazy [2] give an affirmative answer, when $X$ is a Hilbert space. However, the converse is not true in general (see R. Martin [4]). In this paper some sufficient conditions will be given such that $F \neq \phi$. 
Our main results are the following:

THEOREM 1. Let $X$ be a reflexive Banach space. Suppose that for any closed convex set $M$ with the property that $T(t) M \cong M$ for all $t \geqslant 0, M \cap A \neq \phi$. Then $F \neq \phi$. Moreover, $F$ is connected.

THEOREM 2. Let $X$ be a srictly convex reflexive Banach space. If $T$ has a bounded orbit and $L \neq \phi$, then $F \neq \phi$. Moreover, if $t_{i} \uparrow \infty$ and $y=w-\lim _{i \rightarrow \infty} 1 / t_{i} \int_{0}^{t_{i}} T(t) x d t$ for some $x \in X$, then $y \in F$.

As an application of Theorem 1 one can verify that if $X$ is a reflexive Banach space and $T$ has a bounded orbit, then $F \neq \dot{\phi}$ provided that either of the following holds: (i) there is a $t_{0}>0$ such that $T\left(t_{0}\right)$ is weakly continuous function on $X$ or (ii) $X$ has the property that every $m$-dissipative Lipschitz continuous function on $X$ is demiclosed $\left(f\right.$ is demiclosed if $x_{n} \rightarrow x_{0}$ strongly then $y_{0}=f x_{0}$ ). It is known that if $X$ is a uniformly convex space, the condition (ii) is fulfilled, (see F. Browder [1]).

As an application of Theorem 2 one can verify that if $X$ is a strictly convex, reflexive Banach spach and $A \neq \phi$ then $F \neq \phi$. Furthermore, if $x \in A$ then for some unbounded increasing sequence $\left\{t_{i}\right\}$ of positive numbers $\lim _{t_{i} \rightarrow \infty} 1 / t_{i} \int_{0}^{t_{i}} T(u) x d u$ exists and is an element of $F$. This result generalizes that of D. Rutedge [5] in which $X$ is a Hilbert space and $P \neq \phi$.

We need two known lemmas to prove our theorems and we state them below without proof. Lemma 1 was put in the present form by M. Crandall and A. Pazy [2] and Lemma 2 due to R. de Marr [3].

Lemma 1. Let $x \in X$ such that $|T(t) x| \leqslant M$ for all $t \geqslant 0$. Then $K=\bigcup_{\tau \geqslant 0} \bigcap_{t \geqslant \tau}\{y ;|y-T(t) x| \leqslant|x|+M\}$ is a nonempty convex subset of $X$ such that $T(t) K \cong K$ for all $t \geqq 0$.

Lemma 2. (R. de Marr). Let $C$ be a compact subset of $X$ such that $r=\operatorname{diam} C>0$. Then there is an $x_{0} \in \operatorname{clco} C$ and a positive number $r_{1}<r$ such that $\left|y-x_{0}\right| \leqslant r_{1}$ whenever $y \in C$.

We will use the following two lemmas and the above twe lemmas to prove Theorem 1 .

LEMMA 3. Let $M$ be a closed subset of $X$ such that $T(t) M \cong M$ for all $t \geqslant 0$. If $M \cap A \neq \phi$, then there is a compact subset $C$ of $M$ such that $T(t) C=C$. 
Proof. Let $x \in M \cap A$. Then $\bar{O}_{x}$ is a compact subset of $M$ and $T\left(t_{1}\right) \bar{O}_{x} \subseteq T\left(t_{2}\right) \bar{O}_{x}$ whenever $t_{1} \geqslant t_{2} \geqslant 0$. Hence $C=\bigcap_{t>0} T(t) \bar{O}_{x}$ is a nonempty compact subset of $M$. Furthermore, $T(t) C=C$ for all $t \geqslant 0$.

Lemma 4. Let $x_{0}, x_{1} \in X$ and $\lambda \in[0,1]$. Then

$$
M_{\lambda}=\left\{y \in X ;\left|x_{0}-y\right|=\lambda\left|x_{1}-x_{0}\right|,\left|x_{1}-y\right|=(1-\lambda)\left|x_{1}-x_{0}\right|\right\}
$$

is a nonempty closed convex bounded subset of $X$. Moreover, if $x_{0}, x_{1} \in F$ then $T(t) M_{\lambda} \subseteq M_{\lambda}$.

\section{Proof.}

$$
M_{\lambda}=\left\{y \in X ;\left|x_{0}-y\right| \leqslant \lambda\left|x_{0}-x_{1}\right|\right\} \cap\left\{y \in X ;\left|x_{1}-y\right| \leqslant(1-\lambda)\left|x_{0}-x_{1}\right|\right\}
$$

contains $\lambda x_{1}+(1-\lambda) x_{0}$. Thus $M_{\lambda}$ is a nonempty closed convex bounded subset of $X$.

Since $T(t) x_{i}=x_{i}$ for all $t \geqslant 0, i=0,1$ thus for any $y \in M_{\lambda}$,

$$
\left|x_{0}-T(t) y\right|=\left|T(t) x_{0}-T(t) y\right| \leqq \lambda\left|x_{0}-x_{1}\right|
$$

and

$$
\left|x_{0}-T(t) y\right|=\left|T(t) x_{1}-T(t) y\right| \leqslant(1-\lambda)\left|x_{0}-x_{1}\right|,
$$

that is, $T(t) y \in M_{\lambda}$.

Now we prove Theorem 1 .

Proof of Theorem 1. By Lemma 1 there is a nonempty closed bounded convex set $M$ such that $T(t) M \cong M$. Let $\left\{M_{\alpha}\right\}$ be a chain of subset of $M$ such that

(i) $M_{\alpha}$ is a nonempty closed bounded convex set satisfying $T(t) M_{\alpha} \subseteq M_{\alpha}$ for all $\alpha$.

(ii) $M_{\alpha} \subseteq M_{\beta}$ if $\alpha \geqslant \beta$.

Since $M_{\alpha}$ is weak-compact, thus $\bigcap_{\alpha} M_{\alpha} \neq \phi$. Further,

$$
T(t)\left(\bigcap_{\alpha} M_{\alpha}\right) \subseteq \bigcap_{\alpha} M_{\alpha}
$$

By Zorn's lemma there is a maximal element, say $M_{0}$, in the collection $\mathscr{F}=\left\{M_{1} ; M_{1}\right.$ is a nonempty closed bounded convex subset of $M$ such that $\left.T(t) M_{1} \subseteq M_{1}\right\}$. We want to show that $M_{0}$ contains exactly one point. Suppose not. By hypothesis, $M_{0} \cap A$ contains at least one point, say $x$. By Lemma 3 there is a compact subset $C$ of $M_{0}$ such that $T(t) C=C$. By Lemma 2 there is a point $x_{0} \in \operatorname{clco} C \subseteq M_{0}$ such that $\left|y-x_{0}\right| \leqslant r_{1}<r=\operatorname{diam} C$ for all $y \in C$. Consider the set $M^{\prime}=\bigcap_{y \in C}\left\{z \in M_{0} ;|z-y| \leqslant r_{1}\right\}$. 
We see that $M^{\prime}$ is a nonempty closed bounded convex subset of $M_{0}$ such that $T(t) M \cong M$. Since $r=\operatorname{diam} C$ and $C$ is compact, thus there are $x_{1}, x_{2} \in C$ such that $\left|x_{1}-x_{2}\right|=r$. By the definition of $M^{\prime}$ and the fact that $r_{1}<r$, we have $x_{i} \notin M^{\prime}$ for $i=1,2$. Thus $M^{\prime} \neq M_{0}$ and the maximality of $M_{0}$ is contradicted. Thus $M_{0}$ must contain exactly one point which lies in $F$. This shows that if $M$ is a closed convex set satisfying $T(t) M \subseteq M$ for all $t \geqslant 0$ then $M \cap F \neq \phi$.

Next we want to show that $F$ is connected. Suppose not. Then there are two disjoint closed subsets $A$ and $B$ of $X$ such that $A \cup B \supseteqq F, A \cap F \neq \phi$ and $B \cap F \neq \phi$. Let $A^{\prime}=A \cap F$ and $B^{\prime}=B \cap F$. Since $F$ is closed thus $A^{\prime}$ and $B^{\prime}$ are closed. For $x_{1} \in A^{\prime}, D\left(x_{1}, B^{\prime}\right)=$ $\inf \left\{\left|x_{1}-y\right| ; y \in B^{\prime}\right\}=k>0$. Thus, there is a $y_{1} \in B^{\prime}$ such that $\left|x_{1}-y_{1}\right|<5 / 4 K$. It follows from Lemma 4 and the above paragraph there is $z_{1} \in M^{1}=\left\{z \in X ;\left|z-x_{1}\right|=\left|z-y_{1}\right|=1 / 2\left|x_{1}-y_{1}\right|\right\}$ such that $z_{1} \in F=A^{\prime} \cup B^{\prime}$. Since $\left|z_{1}-x_{1}\right|=1 / 2\left|x_{1}-y_{1}\right|<5 / 8 K, z_{1} \in A^{\prime}$. Let $x_{2}=z_{1}$. Then there is a $y_{1} \in B^{\prime}$ such that

$$
\left|x_{2}-y_{2}\right| \leqslant \operatorname{Min}\left\{\frac{5}{4} D\left(x_{2}, B^{\prime}\right),\left|x_{2}-y_{1}\right|\right\} \text {. }
$$

Similarly, there is $x_{3} \in M^{2}=\left\{z \in X ;\left|z-x_{2}\right|=\left|z-y_{2}\right|=1 / 2\left|x_{2}-y_{2}\right|\right\}$ such that $x_{3} \in F$. By the same argument we have $x_{3} \in A^{\prime}$. We assume we have chosen $x_{n+1} \in M^{n}=\left\{z \in X ;\left|z-x_{n}\right|=\left|z-y_{n}\right|=1 / 2\left|x_{n}-y_{n}\right|\right\}$ and $x_{n+1} \in A^{\prime}$ and $y_{n} \in B^{\prime}$ such that

$$
\left|y_{n}-x_{n}\right| \leqslant \operatorname{Min}\left\{\frac{5}{4} D\left(x_{n}, B^{\prime}\right),\left|x_{n}-y_{n-1}\right|\right\}
$$

for all $n \leqslant k-1$ where $k \geqslant 3$. We can choose $y_{k}, x_{k+1}$ as follows:

Since $D\left(x_{k}, B^{\prime}\right) \leqslant\left|x_{k}-y_{k-1}\right|$, there is a $y_{k} \in B^{\prime}$ such that

$$
\left|x_{k}-y_{k}\right| \leqslant \operatorname{Min}\left\{\frac{5}{4} D\left(x_{k}, B^{\prime}\right),\left|x_{k}-y_{k-1}\right|\right\}
$$

and let $x_{k+1} \in A^{\prime}$ such that

$$
x_{k+1} \in M^{k}=\left\{z \in X ;\left|z-x_{k}\right|=\left|z-y_{k}\right|=\frac{1}{2}\left|x_{k}-y_{k}\right|\right\} .
$$

Note that

$$
\begin{aligned}
\left|x_{n+1}-y_{n+1}\right| \leqslant\left|x_{n+1}-y_{n}\right| & =\frac{1}{2}\left|x_{n}-y_{n}\right| \leqslant \cdots \leqslant\left(\frac{1}{2}\right)^{n}\left|x_{1}-y_{1}\right| \\
& <\left(\frac{1}{2}\right)^{n}\left(\frac{5}{4} K\right)
\end{aligned}
$$

and 


$$
\left|x_{n+1}-x_{n}\right|=\left|x_{n+1}-y_{n}\right|<\left(\frac{1}{2}\right)^{n}\left(\frac{5}{4} K\right)
$$

Thus, $\left\{x_{n}\right\}$ is a Cauchy sequence and so $\left\{x_{n}\right\}$ converges to some point, say $x_{0}$ in $A^{\prime}$. Also $D\left(x_{n+1}, B^{\prime}\right) \leqq\left|x_{n+1}-y_{n+1}\right|<(1 / 2)^{n}((5 / 4) K) \rightarrow 0$, so $D\left(x_{0}, B^{\prime}\right)=0$. Since $B^{\prime}$ is closed $x_{0} \in B^{\prime}$. This is a contradiction to $\dot{\rho}=A \cap B \ni x_{0}$. Therefore, $F$ is connected.

In order to prove Theorem 2 we need the following lemmas.

Lemma 5. If $x_{0} \in X$ such that $x_{0}=\lim _{i \rightarrow \infty} T\left(t_{i}\right) x$ for some $x \in X$ and some unbounded increasing sequence $\left\{t_{i}\right\}$ of positive numbers, then there is an unbounded increasing sequence $\left\{s_{i}\right\}$ of positive numbers, such that

$$
\lim _{1 \rightarrow \infty} T\left(s_{i}\right) x_{0}=x_{0}
$$

Indication of proof. By an inductive process, for each $i$, choose $n_{i+1}$ such that $t_{n_{i+1}}-t_{i+1} \geqslant 1+t_{n_{i}}-t_{i}, i=1,2,3, \cdots$ and $n_{1}=1$. Let $s_{i}=t_{n_{i}}-t_{i}$. Then,

$$
\begin{aligned}
\left|T\left(s_{i}\right) x_{0}-x_{0}\right| & \leqq\left|T\left(s_{i}\right) T\left(t_{i}\right) x-x_{0}\right|+2\left|T\left(t_{i}\right) x-x_{0}\right| \\
& =\left|T\left(t_{n_{i}}\right) x-x_{0}\right|+2\left|T\left(t_{i}\right) x-x_{0}\right| \longrightarrow 0 \text { as } i \longrightarrow \infty .
\end{aligned}
$$

That is, $\lim _{i \rightarrow \infty} T\left(s_{i}\right) x_{0}=x_{0}$.

Lemma 6. Let $X$ be a strictly convex Banach space. If

$$
\lim _{i \rightarrow \infty} T\left(s_{i}\right) x_{0}=x_{0}
$$

for some increasing unbounded sequence $\left\{s_{i}\right\}$ of positive numbers, then for any $n$, any $\lambda_{1}, \cdots, \lambda_{n}$ such that $\lambda_{i} \geqslant 0, \sum_{i=1}^{n} \lambda_{i}=1$ and any $x_{1}, \cdots, x_{n}$ in $0_{x_{0}}$,

$$
T(t)\left(\sum_{i=1}^{n} \lambda_{i} x_{i}\right)=\sum_{i=1}^{n} \lambda_{i} T(t) x_{i} \quad \text { for all } t \geqslant 0 .
$$

Indication of proof. Clearly, (1) is true for the case $n=1$. Using inductive argument we may assume that (1) holds for all $n \leqslant k$ where $k \geqslant 1$. We shall show that (1) holds for the case $n=k+1$, that is, for any $\lambda_{i}, \lambda_{i} \neq 1, \sum_{i=1}^{k+1} \lambda_{i}=1$, and any $x_{1}, \cdots, x_{k+1}$ in $0_{x_{0}}$,

$$
T(t)\left(\sum_{i=1}^{k+1} \lambda_{i} x_{i}\right)=\sum_{i=1}^{k+1} \lambda_{i} T(t) x_{i}
$$

Let $y=\sum_{i=1}^{k+1} \lambda_{i} x_{i}, z=\left(1-\lambda_{1}\right)^{-1} \sum_{i=1}^{k+1} \lambda_{i} x_{i}$. Then $y=\lambda_{1} x_{1}+\left(1-\lambda_{1}\right) z$, and 
(2)

$$
\begin{aligned}
\left|T(t) y-T(t) x_{1}\right| & \leqslant\left|y-x_{1}\right|,|T(t) y-T(t) z| \leqslant|y-z| \\
& \text { for all } t \geqslant 0 . \\
\left|T(t) x_{1}-T(t) z\right| & \leqslant\left|T(t) y-T(t) x_{1}\right|+|T(t) y-T(t) z| \\
& \leqslant\left|y-x_{1}\right|+|y-z|=\left|x_{1}-z\right| .
\end{aligned}
$$

Since $\left|T\left(t_{i}\right) x_{1}-T\left(t_{i}\right) z\right| \downarrow\left|x_{1}-z\right|$ as $i \rightarrow \infty$, thus we have

$$
\left|T(t) y-T(t) x_{1}\right|+|T(t) y-T(t) z|=\left|T(t) x_{1}-T(t) z\right| \text {. }
$$

By the strict convexity of $X,(2)$ and (3) we have that

$$
T(t) y=\lambda_{1} T(t) x_{1}+\left(1-\lambda_{1}\right) T(t) z .
$$

By the inductive hypothesis,

$$
T(t) y=\sum_{i=1}^{k+1} \lambda_{i} T(t) x_{i}
$$

Lemma 7. Let $x_{0}, X$ be as in Lemma 6. If there is an unbouded increasing sequence $\left\{u_{i}\right\}$ of positive numbers such that

$$
y=w-\lim _{i \rightarrow \infty} \frac{1}{u_{i}} \int_{0}^{u_{i}} T(t) x_{0} d t \text {, then } y \in F .
$$

Proof. Let

$$
y_{i}=\frac{1}{u_{i}} \int_{0}^{u_{i}} T(t) x_{0} d t
$$

For $\varepsilon>0, r>0$ fixed, there is an $N>0$ such that if $M \geqslant\left|T(t) x_{0}\right|$ for all $t \geqslant 0$,

$$
\frac{r M}{u_{i}}<\frac{\varepsilon}{3} \text { whenever } i \geqslant N \text {. }
$$

It follows from Lemma 6 that

$$
T(r) y_{i}=\frac{1}{u_{i}} \int_{r}^{u_{i}+r} T(t) x_{0} d t=y_{i}+\frac{1}{u_{i}}\left(\int_{u_{i}}^{u_{i}+r}-\int_{0}^{r}\right) T(t) x_{0} d t .
$$

Thus $\left|T(r) y_{i}-y_{i}\right|<2 \varepsilon / 3$ for all $i \geqslant N$. Since $y=w-\lim _{i \rightarrow \infty} y_{i}$, there exists a $k>0, \lambda_{1}, \lambda_{2}, \cdots, \lambda_{k} \geqslant 0$ such that $\sum_{i=1}^{k} \lambda_{i}=1$ and $\left|y-\sum_{i=1}^{k} \lambda_{i} y_{i+N-1}\right|<\varepsilon / 6$. Hence,

$$
\begin{aligned}
|T(r) y-y| \leqslant & \left|T(r) y-\sum_{i=1}^{k} \lambda_{i} T(r) y_{i+N-1}\right| \\
& +\left|\sum_{i=1}^{k} \lambda_{i}\left(T(r) y_{i+N-1}\right)\right|+\left|y-\sum_{i=1}^{k} \lambda_{i} y_{i+N-1}\right| \\
< & 2 \varepsilon / 6+2 \varepsilon / 3=\varepsilon .
\end{aligned}
$$


Since $\varepsilon$ and $r$ are arbitrary positive numbers, thus $y \in F$.

LEMMA 8. Let $\left\{t_{i}\right\}$ be an unbounded increasing sequence of positive numbers and $x$ in $X$. If $T$ has a bounded orbit and

$$
x_{0}=\lim _{i \rightarrow \infty} T\left(t_{i}\right) x,
$$

then

$$
\lim _{u \rightarrow \infty} \frac{1}{u} \int_{0}^{n}\left(T(t) x-T(t) x_{0}\right) d t=0 .
$$

Proof. For $\varepsilon>0$ be given there is an positive integer $n$ such that

$$
\left|T\left(t_{i}\right) x-x_{0}\right|<\varepsilon \quad \text { for all } i \geqslant n .
$$

Let $u$ be any positive number great than $t_{n}$. Then

$$
\begin{aligned}
\left|\frac{1}{u} \int_{0}^{u}\left(T(t) x-T(t) x_{0}\right) d t\right| \leqslant & \frac{1}{u} \int_{0}^{u-t_{n}}\left|T(t) T\left(t_{n}\right) x-T(t) x_{0}\right| d t \\
& +\frac{1}{u} \int_{0}^{t_{n}}|T(t) x| d t+\frac{1}{u} \int_{u-t_{n}}^{u}\left|T(t) x_{0}\right| d t \\
< & \frac{u-t_{n}}{u} \in \\
& +\frac{1}{u}\left(\int_{0}^{t_{n}}|T(t) x| d t+\int_{u-t_{n}}^{u}\left|T(t) x_{0}\right| d t\right) .
\end{aligned}
$$

Since orbits are bounded the last term in above inequality will tend to 0 as $u \rightarrow \infty$. Hence, we prove the assertion.

Proof of Theorem 2. By Lemma 5, Lemma 7 and reflexivity of $X$, there is an increasing unbounded sequence $\left\{u_{i}\right\}$ of positive numbers such that

$$
w-\lim _{i \rightarrow \infty} \frac{1}{u_{i}} \int_{0}^{u_{i}} T(t) x_{0} d t
$$

exists and is in $F$, where $x_{0}=\lim _{i \rightarrow \infty} T\left(t_{i}\right) x$. Also, it follows from Lemma 8

$$
\lim _{i \rightarrow \infty} \frac{1}{u_{i}} \int_{0}^{u_{i}}\left(T(t) x-T(t) x_{0}\right) d t=0
$$

Thus,

$$
w-\lim _{i \rightarrow \infty} \frac{1}{u_{i}} \int_{0}^{u_{i}} T(t) x d t=w-\lim _{i \rightarrow \infty} \frac{1}{u_{i}} \int_{0}^{u_{i}} T(t) x_{0} d t \quad \text { is in } F \text {. }
$$




\section{REFERENCES}

1. F. Browder, Semicontractive and semiaccretive nonlinear mappings in Banach spaces, Bull. Amer. Math. Soc., 74 (1968), 660-665.

2. M. Crandall and A. Pazy, Semigroups of nonlinear contractions and dissipative sets, J. Functional Analysis, 3 (1969), 376-418.

3. R. de Marr, Common fixed points of commuting commuting contraction mappings, Proc. J. Math., 13 (1963), 1139-1141.

4. R. Martin, Lyapunov function and autonomous differential equation in Banach space, to appear in Math. Systems Theory.

5. D. Rutledge, $A$ generator for a semigroup of nonlinear transformations, Proc. Amer. Math. Soc., 20 (1969), 491-498.

Received November 24, 1971. The results are partially based upon the author's Ph. D. thesis, written under the direction of Professor G. F. Webb at Vanderbilt University. This work was supported by N. S. C. Republic of China.

ACAdemia Sinica 


\section{PACIFIC JOURNAL OF MATHEMATICS}

\section{EDITORS}

\author{
H. SAMELson \\ Stanford University \\ Stanford, California 94305 \\ C. R. HоввY \\ University of Washington \\ Seattle, Washington 98105
}

J. DugundJI

Department of Mathematics

University of Southern California

Los Angeles, California 90007

RICHARD ARENS

University of California

Los Angeles, California 90024

\section{ASSOCIATE EDITORS}
E. F. BeCKENBACH
B. H. NEUMANN
F. WOLF
K. YoshidA

\section{SUPPORTING INSTITUTIONS}

UNIVERSITY OF BRITISH COLUMBIA

CALIFORNIA INSTITUTE OF TECHNOLOGY

UNIVERSITY OF CALIFORNIA

MONTANA STATE UNIVERSITY

UNIVERSITY OF NEVADA

NEW MEXICO STATE UNIVERSITY

OREGON STATE UNIVERSITY

UNIVERSITY OF OREGON

OSAKA UNIVERSITY

\author{
UNIVERSITY OF SOUTHERN CALIFORNIA \\ STANFORD UNIVERSITY \\ UNIVERSITY OF TOKYO \\ UNIVERSITY OF UTAH \\ WASHINGTON STATE UNIVERSITY \\ UNIVERSITY OF WASHINGTON

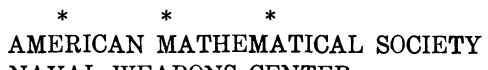 \\ NAVAL WEAPONS CENTER
}

The Supporting Institutions listed above contribute to the cost of publication of this Journal, but they are not owners or publishers and have no responsibility for its content or policies.

Mathematical papers intended for publication in the Pacific Journal of Mathematics should be in typed form or offset-reproduced, (not dittoed), double spaced with large margins. Underline Greek letters in red, German in green, and script in blue. The first paragraph or two must be capable of being used separately as a synopsis of the entire paper. The editorial "we" must not be used in the synopsis, and items of the bibliography should not be cited there unless absolutely necessary, in which case they must be identified by author and Journal, rather than by item number. Manuscripts, in duplicate if possible, may be sent to any one of the four editors. Please classify according to the scheme of Math. Rev. Index to Vol. 39. All other communications to the editors should be addressed to the managing editor, Richard Arens, University of California, Los Angeles, California, 90024.

50 reprints are provided free for each article; additional copies may be obtained at cost in multiples of 50 .

The Pacific Journal of Mathematics is issued monthly as of January 1966. Regular subscription rate: $\$ 48.00$ a year (6 Vols., 12 issues). Special rate: $\$ 24.00$ a year to individual members of supporting institutions.

Subscriptions, orders for back numbers, and changes of address should be sent to Pacific Journal of Mathematics, 103 Highland Boulevard, Berkeley, California, 94708.

PUBLISHED BY PACIFIC JOURNAL OF MATHEMATICS, A NON-PROFIT CORPORATION

Printed at Kokusai Bunken Insatsusha (International Academic Printing Co., Ltd.), 270, 3-chome Totsuka-cho, Shinjuku-ku, Tokyo 160, Japan. 


\section{Pacific Journal of Mathematics}

\section{Vol. 45, No. $2 \quad$ October, 1973}

Kenneth Paul Baclawski and Kenneth Kapp, Induced topologies for quasigroups and loops ............................................. 393

D. G. Bourgin, Fixed point and $\min -\max$ theorems $\ldots \ldots \ldots \ldots \ldots \ldots \ldots$

J. L. Brenner, Zolotarev's theorem on the Legendre symbol ............... 413

Jospeh Atkins Childress, Jr., Restricting isotopies of spheres .............. 415

John Edward Coury, Some results on lacunary Walsh series ................ 419

James B. Derr and N. P. Mukherjee, Generalized Sylow tower groups. II . . . . . . 427

Paul Frazier Duvall, Jr., Peter Fletcher and Robert Allen McCoy, Isotopy Galois

spaces .......................................... 435

Mary Rodriguez Embry, Strictly cyclic operator algebras on a Banach space ... 443

Abi (Abiadbollah) Fattahi, On generalizations of Sylow tower groups ......... 453

Burton I. Fein and Murray M. Schacher, Maximal subfields of tensor products . . 479

Ervin Fried and J. Sichler, Homomorphisms of commutative rings with unit

element .......................................... 485

Kenneth R. Goodearl, Essential products of nonsingular rings ............. 493

George Grätzer, Bjarni Jónsson and H. Lakser, The amalgamation property in

equational classes of modular lattices ...........................

507

$\mathrm{H}$. Groemer, On some mean values associated with a randomly selected simplex

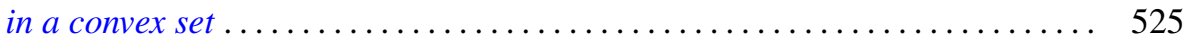

Marcel Herzog, Central 2-Sylow intersections .................... 535

Joel Saul Hillel, On the number of type-k translation-invariant groups ........ 539

Ronald Brian Kirk, A note on the Mackey topology for $\left(C^{b}(X)^{*}, C^{b}(X)\right) \ldots \ldots .543$

J. W. Lea, The peripherality of irreducible elements of lattice.............. 555

John Stewart Locker, Self-adjointness for multi-point differential operators ..... 561

Robert Patrick Martineau, Splitting of group representations ............... 571

Robert Massagli, On a new radical in a topological ring ................. 577

James Murdoch McPherson, Wild arcs in three-space. I. Families of Fox-Artin

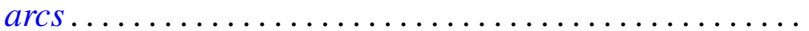

585

James Murdoch McPherson, Wild arcs in three-space. III. An invariant of

oriented local type for exceptional arcs . . . . . . . . . . . . ............ 599

Fred Richman, The constructive theory of countable abelian p-groups ........ 621

Edward Barry Saff and J. L. Walsh, On the convergence of rational functions

which interpolate in the roots of unity ..................

Harold Eugene Schlais, Non-aposyndesis and non-hereditary

decomposability..................................... 643

Mark Lawrence Teply, A class of divisible modules................... 653

Edward Joseph Tully, Jr., H-commutative semigroups in which each

homomorphism is uniquely determined by its kernel ................. 669

Garth William Warner, Jr., Zeta functions on the real general linear group ...... 681

Keith Yale, Cocyles with range $\{ \pm 1\} \ldots \ldots \ldots \ldots \ldots \ldots \ldots \ldots \ldots \ldots \ldots \ldots \ldots . \ldots \ldots$

Chi-Lin Yen, On the rest points of a nonlinear nonexpansive semigroup ........ 699 